\begin{tabular}{|c|c|c|}
\hline$\exists$ & $\begin{array}{c}\text { International Journal of Current Research } \\
\text { and Academic Review }\end{array}$ & 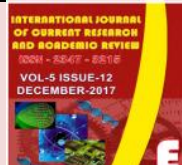 \\
\hline $\begin{array}{l}\text { EXCELLENT } \\
\text { PUBLISHERS } \\
\end{array}$ & $\begin{array}{c}\text { ISSN: 2347-3215 (Online) } \\
\text { Journal homepage: http://www.ijcrar.com }\end{array}$ & \\
\hline
\end{tabular}

doi: https://doi.org/10.20546/ijcrar.2017.512.007

\title{
Effectiveness of Punica granatum Linn Extract Compared to Ellagic Acid on Inhibition of Oral Squamous Cell Carcinoma through Apoptotic Expression Analysis
}

\author{
Sri Hernawati ${ }^{*}$, FX Ady Soesetijo ${ }^{2}$ and Winny Adriatmoko ${ }^{3}$ \\ ${ }^{1}$ Departement of Oral Medicine, Faculty of Dentistry, Jember University, Jember 68121 - Indonesia \\ ${ }^{2}$ Departement of Prosthodontics, Faculty of Dentistry, Jember University, Jember 68121- Indonesia \\ ${ }^{3}$ Departement of Oral Surgery, Faculty of Dentistry, Jember University, Jember 68121- Indonesia
}

*Corresponding author

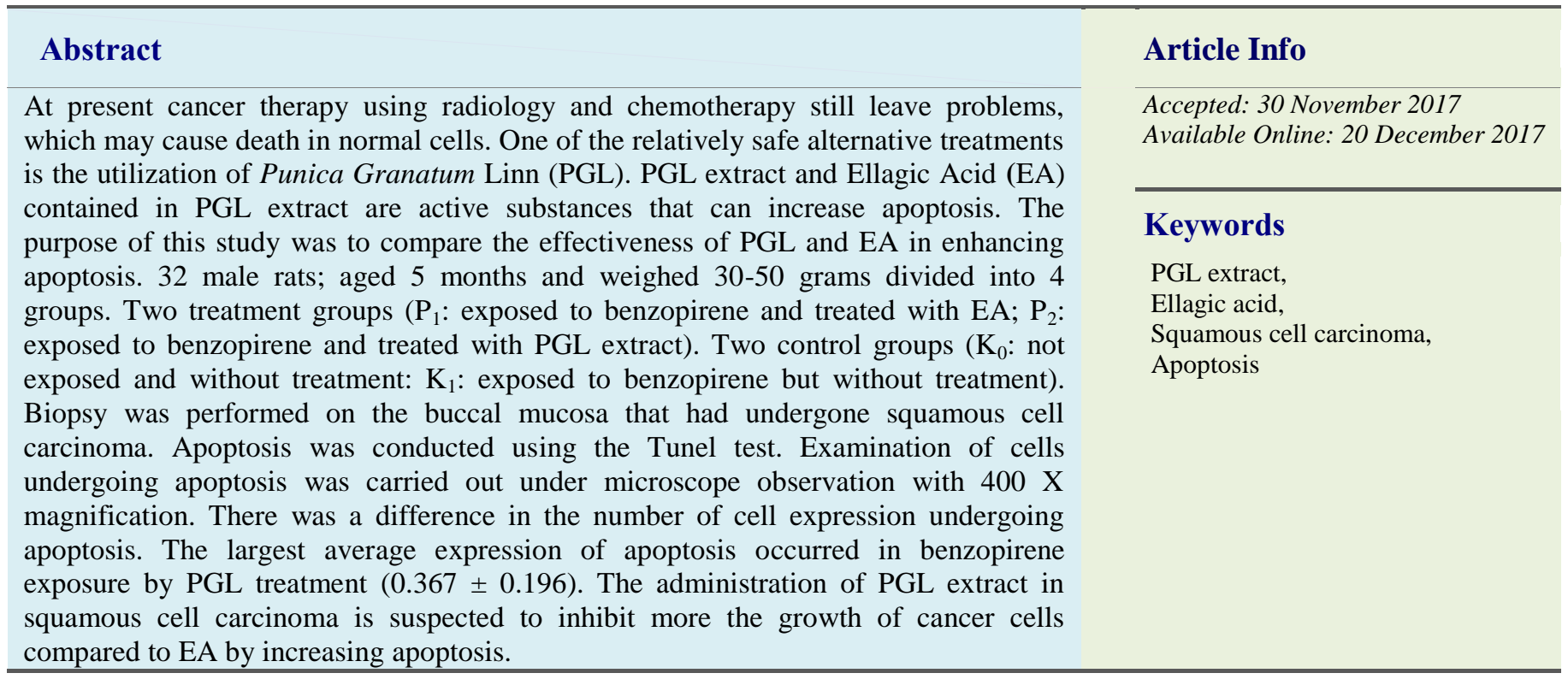

\section{Introduction}

Squamous cell carcinoma is one of the causes of death in developing countries. Oral cavity cancer has a microscopic view of the proliferation of atypical cells with changes in the form of rete pegs processus; abnormal keratinization; basaloid cell proliferation; the arrangement of irregular cells and forming tumor nest that infiltrate to surrounding tissue. The growth of carcinoma is influenced by exogenous and endogenous factors that may lead to abnormal protein function due to gene mutation. Genetic control programmed against cells that are less potent and harmful to the body may be performed by apoptosis. Imperfect apoptosis affects the cell cycle, which may contribute to the growth and development of squamous cell carcinomas (Wusheng et al., 2011).

The process of carcinogenesis and the development of cancer generally occurs due to gene mutation. The genes that facilitate the process of carcinogens and the development of cancer are oncogenes (BCl-2, c-myc, 
fos, jun, MDM-2 and race), while those inhibiting carcinogenic processes are supressor genes (Bax and p53). DNA damage can cause p53 mutations, consequently p53 loses its function as a gene that induces apoptosis. In addition, there will be a decrease in Bax expression that plays a role in the induction of apoptosis (Boik, 2001).

Apoptosis may occur physiologically and pathologically. Physiological apoptosis is the process of cell death in order to maintain the integrity of the body as a whole and play an important role in maintaining homeostasis.

While pathological apoptosis is cell death due to stimulation and roles in preventing the growth of potentially harmful cells (Rajesh et al., 2009).

Various attempts to manage cancer e.g. radiology and chemotherapy still encounter many obstacles. These therapies may have an effect on normal cell death. At this time the treatment efforts that have been developed is the utilization of phytopharmaca, which explores the chemical elements in plants that are potentially efficacious as medication. One of the medicinal plants that may be used for cancer therapi is Punica Granatum Linn (PGL) (Landsy \& Newman, 2007; Rocha et al., 2012).

The PGL that can be used for cancer therapy is a whole extract of PGL and a single preparation of EA which is an active substance in the whole extract of PGL. PGL extract and standardized EA have pharmacological potential for cell carcinoma inhibition (Jurenka, 2008; Saifudin et al., 2011).

PGL extract contains the active substance of EA, which binds together with flavonoid compounds and hydrolyzable tannins. EA in free form and single-dose with a concentration of $40 \%$ may detoxify carcinogens and inhibit the rate of cancer cell proliferation (Wusheng et al., 2011; Jurenka, 2008).

This study was aimed at examining the effectiveness of PGL extract compared to EA in eradicating oral cancer cells through analysis of apoptotic expression.

\section{Materials and Methods}

The type of this study was laboratory experimental, with a post test only control group design (figure 1). Rats as samples were Swiss Webster strains (Balb / c); aged 5 months; male and weighed ranging from 30 - 50 grams.
The number of samples was 32 rats divided into 4 groups (@ 8 samples). Three groups (24 samples) were conditioned to develop squamous epithelial cell cancer by injection of a benzopirene solution in olivarum olium (0.04 mg: $0.04 \mathrm{ml}) 3$ times a week for 4 weeks. $\mathrm{C}_{0}$ : normal rat group; $\mathrm{C}_{1}$ : rats with cancer without PGL extract or EA therapy; $\mathrm{T}_{1}$ : cancer-infected rats treated with EA therapy; $\mathrm{T}_{2}$ : cancer-infected rats were administered with PGL extract. PGL extract and EA in this study were commercial products manufactured by $\mathrm{Xi}$ an Biof Biotechnology Co. Ltd. (Room 1-1111, Hightech Venture Park, No. 69 Jinye Road Gaoxin, District of Xian, People's Republic of China). Therapy using EA and PGL extract were administered orally, each with a dose of $75 \mathrm{mg} / \mathrm{kg} / \mathrm{bw} /$ day dissolved into $0.3 \%$ CMC-Na. The above therapy was performed once daily for 4 weeks. At the end of the $9^{\text {th }}$ week the biopsy was conducted on the mucosal tissue of the oral cavity of the rats, and they were subsequently sacrificed.

Examination of apoptotic expression using Terminal deoxynucleotidyl Transferasemediated dUTP Nick End Labeling (TUNEL) assay, using materials i.e. The TUNEL Apoptosis Detection Kit for paraffin block tissue (Biotin-labeled POD), Cat. No. L00296, Gen Script USA.

A $400 \mathrm{x}$ light microscope (Olympus BX-50 Japan) magnification was used to observe cells apoptosis, which in the nucleus was conspicuous brown-blackish. Percentage $(\%)$ of Apoptosis = number of apoptotic positive cells / total number of cells x $100 \%$.

The data was analyzed by One Way Anova, then continued by multiple comparison test of Least Significance Different with significance level 95\% ( $\alpha=$ $0,05)$.

This research has been approved for ethical feasibility from the Research Ethics Commission of Airlangga University Surabaya Number: 16 / KKEPK.FKG / II / 2016

\section{Results and Discussion}

The results showed that administration of PGL extract in $\mathrm{P} 2$ group was the most effective in eradicating cancer cells by increasing apoptosis expression compared to other groups (table 1). Seeram et al., ${ }^{7}$ states that the synergicity between the active compounds contained in PGL extract, including flavonoids, punialagin, anthocyanidine and EA has potential anti-cancer activity. 
The tunel staining can known apoptosis expression of each group treatment. The most expression was shown by treatment group with the PGL extract, while in the group with benzopirene exposure showed negative apoptosis expression (figure 2).

Polyphenols, which is rich of flavonoids, contained in pomegranates have anti-invasive, anti-eicosanoid, antiangiogenic activity and are stimulating apoptosis in breast and prostate cancer cells in vitro. Pomegranate may inhibit angiogenesis through regulation of vascular growth factor (VEGF) in breast cancer because the production of angiogenic factors is regulated by NF-Kb (Seeram et al., 2016).

Standardized PGL extracts with EA concentrations of $40 \%$ exhibit anti-proliferative effects, induce apoptosis and inhibit in vitro cancer cell development (Jurenka, 2008). Whereas Kholifah ${ }^{8}$ states that standardized PGL extracts as mentioned above at a dose of $250 \mu \mathrm{g} / \mathrm{ml}$ may increase apoptosis in squamous cell carcinoma human tongue. Saefudin et al., (2011), states that the standardization of EA with a concentration of $40 \%$ shows a pharmacologically most potent concentration of cell carcinoma inhibition.

Cancer is characterized by uncontrolled cell proliferation and inhibited apoptosis. Immortal cells, invasion and metastasis to other organs. Apoptosis is a process of programmed cell death that occurs regularly to remove unnecessary cells without an inflammatory response (Elmore, 2007). Apoptosis occurs normally during development and aging. This mechanism is a homeostasis mechanism to maintain cell populations within the tissues. Apoptosis also functions as a defense mechanism as in immune reactions or when cells are damaged by a disease or toxic gene. Characteristics of apoptosis are DNA fragmentation, chromatin condensation, cytoplasmic shrinkage and cells will die without lysis, so as not to damage the surrounding cell or tissue (Elmore, 2007; Mohammad, 2002).

Apoptosis is the process of cell death in order to maintain the integrity of the body as a whole. This program has an important role to maintain cellular proliferation homeostasis. One of the important roles of apoptosis is to limit excessive cell proliferation in cancer cells (Salido \& Rosado, 2009). Multi-functional targets and activation of some apoptotic pathways are important in cancer therapy to prevent the development of medication resistance in cancer therapy (Mohammad, 2002).

Each cell will respond to all stress or stimulus received in various ways, either through activation of the life signal until the initiation of cell death. The purpose of the process is to maintain homeostasis, thus unnecessary cells will be eliminated. The mechanism depends on a variety of factors and the ability of cells to cope with stress or stimulus (Edderkaoui, 2008). The stimulus applied in this study was the administration of PGL extract showing that it could increase apoptosis.

Apoptosis is an efficient mechanism to eliminate unnecessary and possibly harmful cells that may save the organism. Failure may occur in the apoptosis process leading cancer, because cells that undergo a continuous mutation will replicate uncontrollably. Wild p53 is a gene suppressor tumor that will be activated if the cell has a gene defect. This wild p53 function prevents replication of damaged or mutated cells by genetically terminating the cell cycle in G1 or interphase, thus the cell has time to repair. In addition, this gene also serves to trigger apoptosis (Kresno, 2011; Lumangga, 2008).

Table.1 Mean \pm SD apoptosis expression of squamous cell carcinoma

\begin{tabular}{|l|c|}
\hline \multicolumn{1}{|c|}{ Group } & Apoptosis exspression \\
\hline Control (-) / K0 & $0.083 \pm 0.132^{\mathrm{a}}$ \\
\hline $\begin{array}{l}\text { Control (+) / K1 } \\
\text { (benzopirene + CMC) }\end{array}$ & $0.050 \pm 0.054^{\mathrm{a}}$ \\
\hline P1 / (benzopirene + EA) & $0.233 \pm 0.081^{\mathrm{b}}$ \\
\hline P2 / (benzopirene + PGL) & $0.367 \pm 0.196^{\mathrm{c}}$ \\
\hline
\end{tabular}

Notes: Different superscripts show significant differences $(\mathrm{p}<0,05)$ based on multiple comparisons test 


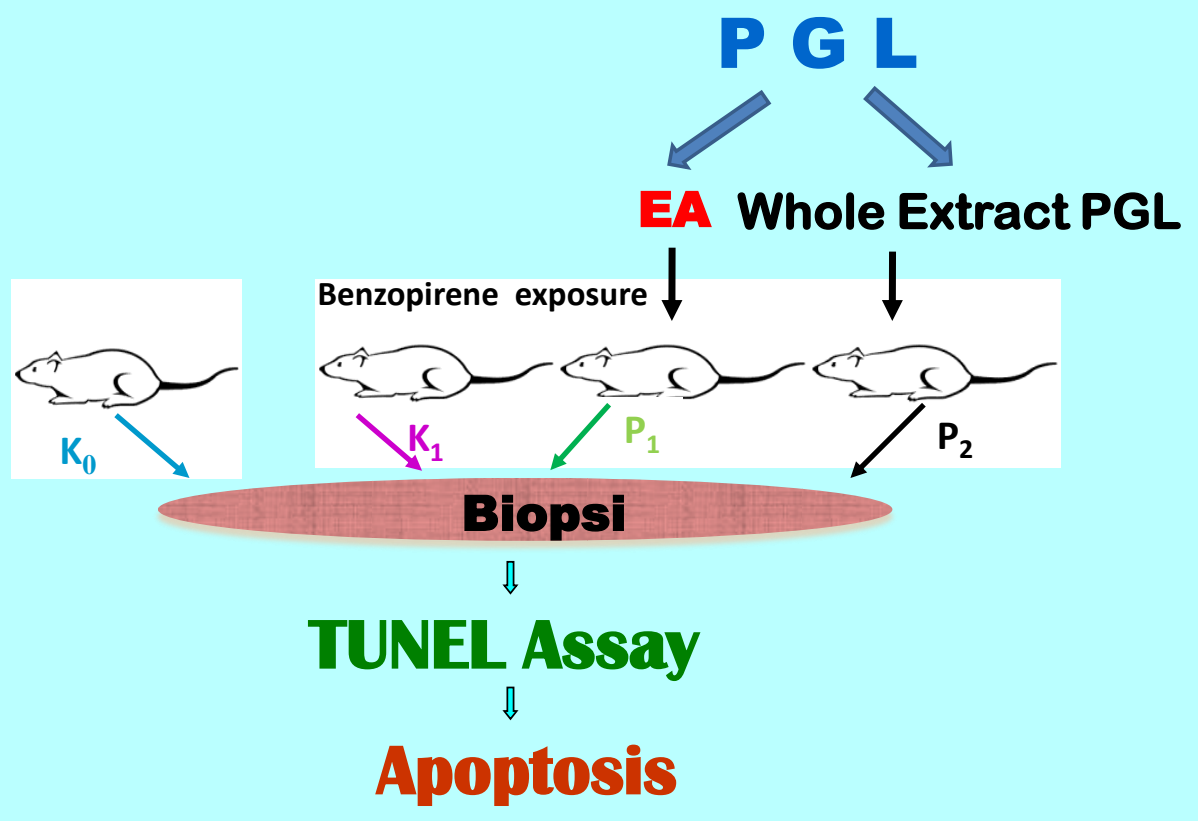

Figure 1. Experimental Design
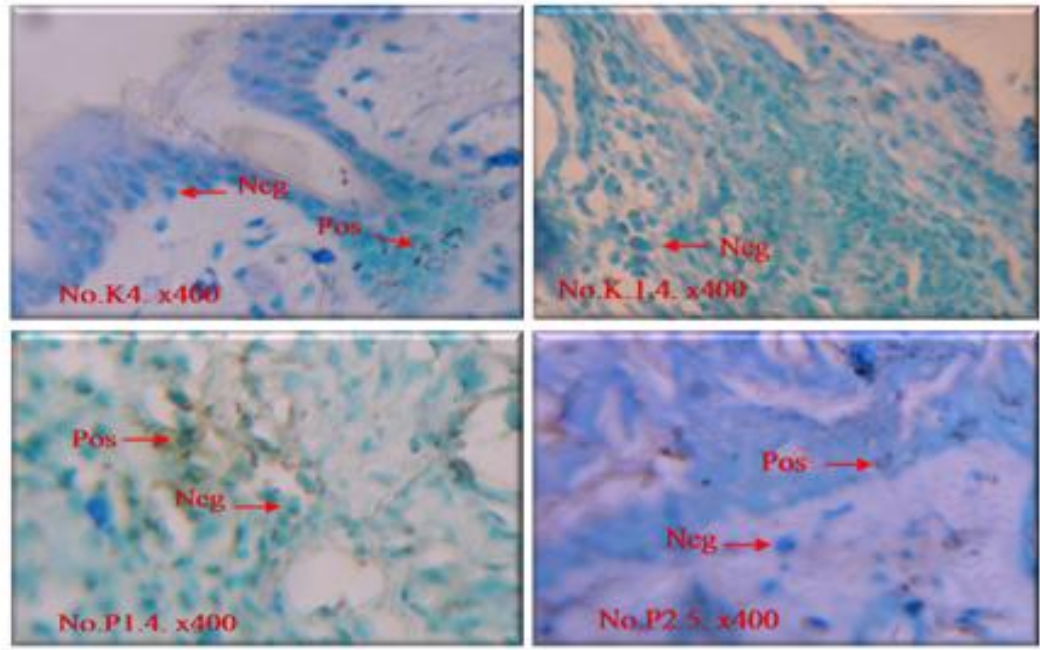

Figure 2. Ap op to sis Exp ression of squamo us cell carcinoma (magnitude $400 \mathrm{X}$ )

\section{Notes:}

a. Negative control (K4) on nomal cell

b. Positive control (K1.A) on cell with benzop irene exp osure

c. Treatment group (P1 A) on cell with benxop irene + EA

d. Treatment group (P25) on cell w ith benzopirene + PGL

EA in vitro studies showed that it may increase the expression of death receptors e.g. TRAIL R2/DR5. DR5 binds death stimuli and leads to pro-caspase activation 6 . Cross talk between special pathways of extrinsic apoptosis (via death receptors) and intrinsic pathways through mitochondria. EA may inhibit the expression of IAP protein and XIAP protein expression in in vitro studies, most cancers show over the expression of IAP and XIAP proteins. IAP protein to protect cancer cells from death stimuli, as a result some anti-cancer therapy target inhibits IAP expression to eradicate cancer cells. XIAP is the strongest apoptotic suppressor, XIAP binds and inhibits caspase-3, caspase-7 and caspase-9, with the elagic acid effect that may inhibit XIAP, apoptosis may occur (Samali, 2010). 
EA (C141-1608) in vitro in paCa-2 cells inhibits the activity of NF-kB transcription factor. NF-kB is a major transcription factor that usually has an anti-apoptotic role in cancer cells. NF-kB inhibits apoptosis by increasing the activity of $\mathrm{BCl}-2$ (anti apoptosis). $\mathrm{BCl}-2$ inhibits mitochondrial permeability that inhibits the release of Cytochrome-C and suppresses Bax. EA decreases NF-kB activity, causes $\mathrm{BCl}-2$ to decrease, mitocondrial apoptotic pathway activity, Cytochrome-C release and caspase activation (Edderkaoui, 2008; Marco \& Naval, 2008).

In vitro studies of PC-3 cancers show that PGL extract can inhibit the growth of mutated cells and induce apoptosis through protein modulation that regulates apoptosis (Jurenka, 2008).

In comparison, PGL was stronger in activity as antiproliferative, inducing apoptosis and anti-oxidants compared to that in EA activity. Compared to EA and polyphenols in LNCap-AR cell line showed that PGL is a strong inhibitor to inhibit cancer cell growth and induce apoptosis (Bisen et al., 2012; Adhani et al., 2009).

Group $\mathrm{K}_{0}$ (without benzopirene and without treatment) has low apoptosis, group $\mathrm{K}_{0}$ is the normal group physiologically the growth system of cells in the individual is governed by a balance between apoptosis and proliferation.

EA may induce apoptosis and G1 retention of T24 bladder T24 cells in human. Most studies are still in vitro, the weaknesses of in vitro studies i.e. sensitivity and specific reactions do not reflect actual results and do not necessarily reflect the results of the study in vivo. Thus it encourages researchers to conduct in vivo research on animal model. In addition, various studies that have been conducted on PGL activity against apoptosis do not explain the mechanism of apoptosis.

This study showed that PGL extract is stronger than ellagic acid. It is caused by some chemical compound contained in whole extract (ellagic acid, caffeic acid, luteolin and punicid acid) can work synergistically. Whereas EA is sisceptible to transformation, biodegradation and low solubility in water, as well as difficult absorption in the intestinal. Seeram et al., (2005), states that individually each of the active ingredients contained in the whole extract of the pomegranate has the potential of antiapoptosis, but when combined the effects are multiplied.
Studies on the effectiveness of PGL extract compared to EA on the inhibition of oral squamous cell carcinoma through apoptotic expression analysis have been performed. In this study it can be concluded that PGL extract may eradicate oral squamous cell carcinoma higher compared to EA through apoptosis expression. The mechanism of action of PGL extract to induce apoptosis is by the synergicity of chemical compound contained in it.

\section{References}

Adhani V.M., Khan N., Mukhtar H., 2009. Cancer chemoprevention by pomegranate: laboratory and clinical evidence. Nutr. Cancer. 61(6): 811-815.

Bisen P.S., Bundela S.S., Sharma A., 2012. Ellagic acid - chemopreventive role in oral cancer. J. Cancer Sci. Ther., 4: 020-030.

Boik J., 2001. Natural compound in cancer therapy: promising nontoxic antitumor agents from plants \& other natural sources. Quality book inc, Minnesota. Pp.13-27.

Edderkaoi M., Odinokova I., Gukovskaya A.S., 2008. Ellagic acid induced apoptosis through inhibition of nuclear factor $\mathrm{kB} \mathrm{n}$ pancreatic cancer cells. WJG, 14(23): 3672-3680.

Elmore S., 2007. Apoptosis a review of programmed cell death. Toxocol. Pathol, 35: 495-516.

Jurenka J., 2008. Therapeutic application of pomegranate (punica granatum L): A review. Altern Med. Rev., 13(2): 128-144.

Kresno S.B., 2011. Text book ilmu dasar onkologi. Edisi ke dua. Badan penerbit Universitas Indonesia, Jakarta. Pp. 66-129.

Landsky E.P. and Newman R.A., 2007. Punica granatum (pomegranate) and its potential for preventive and treatment of inflammation and cancer. $J$. Ethnophamaceol., 109: 177-206.

Lumangga F., 2008. Apoptosis. J. Patol. Anatom. Pp. 17.

Marco L. and Naval J., 2008. BCl-2 family members as molecular targets in cancer therapy. J. Biochem. Pharm., 76: 936-946.

Mohammad H.F., 2002. Ellagic acid mediated CK-2 inhibition; a natural, multifunctional strategy to trigger cervical cancer cell death in vitro and in vivo. Ohio, USA., Ph.D. Disertation, Cleleland University, Ohio, USA.

Rajesh P. Rastogi, Richa and Rajeshwar P. Sinha. 2009. Molecular mechanism and pathogenicity. EXCLI J., 8: $155-181$. 
Rocha A., Wang L., Penichet M., Green M.M., 2012. Pomegranate juice and specific components inhibit cell and molecular processes critical for metastasis of breast cancer. Breast Cancer Res. Treat., 136(3): 647-658.

Saifudin A., Rahayu V., Teruna H.Y. 2011. Texbook standardisasi bahan obat alam. Edisi pertama. Graha ilmu, Jombang. Pp. 1-26.

Salido G.M., Rosado J.A., 2007. Apoptosis: involvement of oxidative stress and intracellular $\mathrm{Ca}^{2+}$ homeostasis. Springer Science, Spain. Pp. 1-17.

Samali A., Fulda S., Adrienne M.G., Osamu H., Srinivasula S.M., 2010. Cell stress and cell death. Int. J. Cell Biol. Pp. 1-6.
Seeram N.P., Adam I.S., Henning S.M., Niiu Y., Zhang Y., Nair M.G., Heber D., 2005. In vitro antiproliferative, apoptosis and antioxidant activities of punicalagin, allagic acid and a total pomegranate tannin extract are enhanced in combination with other polyphenol as found in pomegrate juice. $J$. Nutr. Biochem, 16(6): 360-367.

Seeram N.P., Schulman R.M., Heber D., 2006. Pomegranate ancient roots to modern medicine. $1^{\text {st }}$. Taylor and Francis Group, New York. Pp. 2-99.

Wusheng Yan, Ignatio I. Wistuba, Michael R. EmmertBuck, Heidi S. Erickson., 2011. Squamous cell carcinoma - similarities and differences among anatomical sites.Am. J. Cancer Res., 1(3): 275-300.

\section{How to cite this article:}

Sri Hernawati, FX Ady Soesetijo and Winny Adriatmoko. 2017. Effectiveness of Punica granatum Linn Extract Compared to Ellagic Acid on Inhibition of Oral Squamous Cell Carcinoma through Apoptotic Expression Analysis. Int.J.Curr.Res.Aca.Rev. 5(12), 46-51. doi: https://doi.org/10.20546/ijcrar.2017.512.007 